\title{
Age-dependent radiation dose due to uranium in public drinking water in Hyderabad, India
}

\author{
S.K. SRIVASTAVA ${ }^{1}$, A.Y. BALBUDHE ${ }^{1}$, K. VISHWAPRASAD ${ }^{1}$, \\ P. PADMA SAVITHRI ${ }^{1}$, R.M. TRIPATHI ${ }^{2}$, V.D. PURANIK ${ }^{2}$ \\ (Manuscript received 29 June 2011, accepted 23 October 2011) \\ ABSTRACT A study was done to evaluate the ingestion dose due to uranium in drinking water. \\ The area of study is the twin cities of Hyderabad and Secunderabad, India. The \\ uranium concentration in water samples was analysed by laser-induced fluorimetry. \\ The associated age-dependent radiation dose was estimated by taking the prescribed \\ water intake values and dose conversion factors for different age groups. The \\ concentration of uranium varies from below the detection limit (detection limit $=$ \\ $0.20 \mu \mathrm{g} . \mathrm{L}^{-1}$ ) to $2.50 \pm 0.18 \mu \mathrm{g} . \mathrm{L}^{-1}$, with a geometric mean of $0.67 \mu \mathrm{g} . \mathrm{L}^{-1}$ in tap water, \\ whereas in groundwater the range is $0.60 \pm 0.05$ to $82 \pm 7.1 \mu \mathrm{g} . \mathrm{L}^{-1}$ with a geometric \\ mean of $10.07 \mu \mathrm{g} . \mathrm{L}^{-1}$. The annual ingestion dose by the drinking water pathway due \\ to uranium in tap water for various age groups was found to vary from 0.23 to \\ $6.35 \mu S v \cdot y^{-1}$ with an average of $1.08 \mu S v . y^{-1}$. The ingestion dose due to uranium in \\ tap water is $\mathbf{1 5}$ times lower than that of groundwater consumption.
}

Keywords: Uranium / dose / drinking water/fluorimeter

RÉSUMÉ Dose age de rayonnement dépendante due à l'uranium dans l'eau potable publique à Hyderabad, Inde.

Une étude a été réalisée pour évaluer la dose résultant de l'ingestion d'uranium dans l'eau de boisson. La zone d'étude est constituée des villes jumelles d'Hyderabad et Secunderabad en Inde. La concentration en uranium dans des échantillons d'eau a été analysée par fluorimétrie induite par laser. La dose efficace associée a été estimée en fonction de lâge suivant des valeurs de référence pour la consommation d'eau et les facteurs de conversion de dose pour différents groupes d'âge. La concentration en uranium varie de la limite de détection (limite de détection $=0,20 \mu \mathrm{g} . \mathrm{L}^{-1}$ ) à $2,50 \pm$ $0,18 \mu \mathrm{g} . \mathrm{L}^{-1}$, avec une moyenne géométrique de $0,67 \mu \mathrm{g} . \mathrm{L}^{-1}$, dans l'eau du robinet alors que la fourchette pour l'eau souterraine est de $0,60 \pm 0,05$ à $82 \pm 7,1 \mu \mathrm{g} . \mathrm{L}^{-1}$ avec une moyenne géométrique de $10,07 \mu \mathrm{g} . \mathrm{L}^{-1}$. La dose annuelle par ingestion d'uranium via l'eau du robinet pour les divers groupes d'âge varie de 0,23 à $6,35 \mu \mathrm{Sv}$ par an avec une moyenne de $1,08 \mu \mathrm{Sv}$ par an. La dose par ingestion due à l'uranium dans l'eau du robinet est $\mathbf{1 5}$ fois inférieure à celle de la consommation d'eau souterraine.

\footnotetext{
Health Physics Unit, NFC, Environmental Assessment Division, Bhabha Atomic Research Centre, PO: ECIL, Hyderabad 500062, India.

2 Environmental Assessment Division, Bhabha Atomic Research Centre, Trombay, Mumbai 400085, India.
} 


\section{Introduction}

Uranium has prevailed in the atmosphere, hydrosphere, lithosphere and biosphere with wide variations in concentration since the inception of the earth. Uranium is present in rock, soil and natural materials, and is found in small quantities in air, water and food that people are always in contact with (US DOE, 2001). The presence of uranium in the aquatic environment is due to leaching from natural deposits, combustion of coal and other fuels, and the use of phosphate fertilisers (Essien et al., 1985; Tadmor, 1986). This radioactive substance in groundwater is an unwanted and involuntary risk factor from natural sources, not artificial sources. The general population inescapably (Almgren et al., 2008) receives some quantity of radiation dose due to its radioactive properties. The uranium levels vary from region to region depending on the geology, geography and geochemistry. Uranium dissolves readily in oxygen-rich water, which accounts for its presence in surface water, groundwater and the sea. Water being an essential part of the human diet causes chronic natural radioactivity exposure. Worldwide natural radioactivity in drinking water is monitored for assessment of the radiation doses and health risk to the general population. Exposure to naturally occurring radionuclides by water intake may be controlled by water safety regulations (ICRP, 1999). Water consumption depends on various factors such as age, sex, body weight, metabolic activity, etc. Uranium is also a wellknown nephrotoxic heavy metal exerting detrimental health effects by chemical action mostly in the proximal tubules of the kidneys of humans. Thus, estimation of uranium content in drinking water is required for assessment of health risk. Hyderabad is situated on the Deccan Plateau in the southern part of India. Geologically Hyderabad is situated on granite gneiss formations of archaean and proterozoic rocks covering a vast time span from 3800 to 570 million years. Hyderabad is the sixth most populated city of India, with a population of 5.5 million (as per the census in 2001, India) spread over an area of around $173 \mathrm{~km}^{2}$. The main source of drinking water for the city is tap water from local supply systems. The systems draw their supply from surface water sources. These sources are dams on rivers or rainwater collection lakes located around Hyderabad. In most cases, urban people use groundwater less often in the forms of communal or individual wells than rural people for drinking purposes. Therefore, the size of the exposed population consuming groundwater is very small in the study area. This work deals with the estimation of the radiation dose for different age groups due to intake of uranium through water. The dose was estimated for tap water and groundwater in the case of consumption. 


\section{Materials and methods}

\subsection{Sample collection}

One hundred samples of tap water from user points along with fifty-one groundwater samples from bore wells were collected from different parts of the city of Hyderabad, India. The main source of tap water is municipally supplied water, packaged drinking water and commercially available household water purifiers. Groundwater samples were procured from bore wells with a hand pump and/or electric pump from residential areas, at varying depths.

One litre of water sample was collected in an acid pre-cleaned polyethylene container to avoid wall deposition.

\subsection{Instrumentation}

Out of many available analytical techniques, the most widely used for determination of uranium are UV fluorimetry, laser fluorimetry, ICP-MS, alpha spectrometry, etc. Here, estimation of the uranium concentration in groundwater and tap water was carried out by laser-induced fluorimetry, provided by the Raja Ramanna Centre for Advanced Technology, Department of Atomic Energy, India, which is one of the most sensitive, accurate and precise techniques, with a detection limit of $0.2 \mu \mathrm{g} . \mathrm{L}^{-1}$. The method is based on the luminescence property of the uranyl ion in solution. The instrument consists of a sealed-off molecular nitrogen laser tube as the excitation source, a sample compartment and a photomultiplier tube (PMT) as a radiation transducer.

To avoid the background signal due to the source the PMT is aligned at a right angle to the radiation source, which enables improving the detection level.

Organic matter has a very short fluorescence lifetime (100 ns) compared with that of uranyl complexes $(200 \mu \mathrm{s})$. Hence, a delayed fluorescence measurement technique was utilised to avoid interference due to the presence of organic matter in the sample, if any.

The fluorescence peak of organic matter is around $400 \mathrm{~nm}$ and those of uranium in complexing media are 494, 516, 540 and $565 \mathrm{~nm}$, with a maximum around $510 \mathrm{~nm}$ (Veselsky et al., 1988). Therefore, using an optical filter at $450 \mathrm{~nm}$, the contribution of organic matter is nullified.

Thus, the fluorescence interference due to organic matter is corrected by using the proper optical filter, a fixed electronic delay and gating technology. 


\subsection{Reagents and chemicals}

Groundwater and tap water samples were directly analysed. A standard stock solution of 1.04 g.L $\mathrm{L}^{-1}$ uranium was diluted to working concentrations for regular calibration of the system. Sodium pyrophosphate $(0.01 \mathrm{M})$ was used as the fluorescence-enhancement reagent and for the formation of the uranyl complex because uranyl phosphate complexes are stable (Sahoo et al., 2008).

\subsection{Analytical procedure}

A suitable aliquot of water sample was placed in a dry and clean cell along with $0.01 \mathrm{M}$ sodium pyrophosphate $(\mathrm{pH} 7)$ and fluorescence counts were measured. The laser fluorimeter was calibrated with standard uranium solution of a known concentration. Field samples were analysed using the standard addition method in order to avoid the matrix effect because the samples were from different parts of the city and the chemical constituents may vary significantly. Both micropipettes and an analytical balance were used simultaneously to avoid any error in pipetting. The details of the optimisation method and analysis protocol are given elsewhere (Rathore et al., 2001).

\subsection{Quality control assurance and quality control}

All laboratory glassware used for sample processing was soaked in $10 \%$ nitric acid for $15 \mathrm{~d}$ and then rinsed thoroughly with distilled and double-distilled water, respectively, before use. A reagent blank was taken along with each batch of sample preparation for blank correction. Various precautions were taken in order to achieve a dust-free laboratory environment and a steady temperature. The method was cross-checked for accuracy and reliability. Randomly selected groundwater and tap water samples were analysed by both conventional UV fluorimetry following solvent extraction and laser fluorimetry. The results are observed to be in good agreement with a correlation coefficient of 0.99 (Fig. 1).

\subsection{Radiation dose evaluation}

The radiation dose was evaluated due to intake of uranium through the drinking water pathway. The dose was calculated for tap water and also for groundwater, in the case where it is used for drinking. ICRP dose coefficients (ICRP 71, 1995 ; ICRP $72,1995)$ and prescribed water intake rates for different age groups were used for estimation of the radiation dose. The annual radiation ingestion dose due to uranium intake through the drinking water pathway was calculated by the relation :

Ingestion dose $\left(\right.$ Sv. $\left.y^{-1}\right)=$ Concentration $\left(\right.$ Bq..$\left.^{-1}\right) \times$ Intake $\left(1 . y^{-1}\right) \times$ Dose coefficient $\left(\mathrm{Sv} \cdot \mathrm{Bq}^{-1}\right)$. 


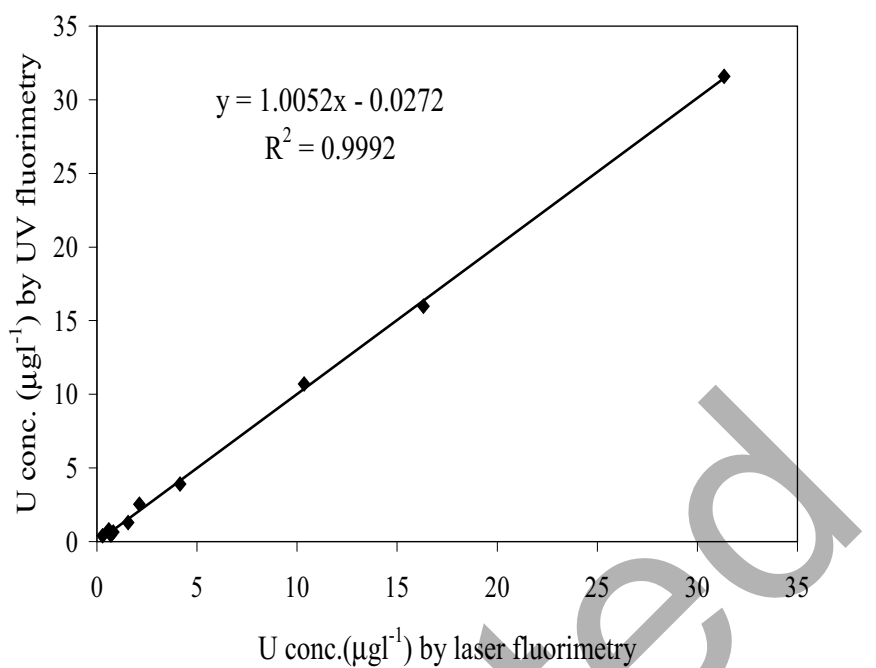

Figure 1. Comparison of uranium concentration by two techniques: laser fluorimetry and conventional UV fluorimetry.

The water intake rates considered for infants ( $0-6$ months old) and children (7-12 months old) were 0.7 and $0.81 . \mathrm{d}^{-1}$, respectively. For the age groups of $1-3$, 4-8 and $>18$ years old, the water intake rates considered were $1.3,1.7$ and $3.71 . \mathrm{d}^{-1}$, respectively (www.nap.edu; Bronzovic and Marovic, 2005). Men usually require more water than women because they have more lean muscle. In the present study, natural isotopic abundance of uranium was assumed with an activity-to-mass factor of $24.5 \mathrm{mBq} \cdot \mu^{-1}$ (USEPA, 2000).

\section{Results and discussion}

\subsection{Tap water}

Concentrations of uranium in tap water samples collected from different parts of the city were found to vary from below the detection level (BDL) to $2.50 \pm$ $0.18 \mu \mathrm{g} . \mathrm{L}^{-1}$ with a geometric mean $(\mathrm{GM})$ of $0.67 \mu \mathrm{g} . \mathrm{L}^{-1}$, which is well within the guideline value given by the World Health Organization (WHO) $\left(15 \mu \mathrm{g} . \mathrm{L}^{-1}\right)$ and United States Environmental Protection Agency (USEPA) $\left(30 \mu \mathrm{g} . \mathrm{L}^{-1}\right)$. The frequency distribution of uranium for the tap water samples is shown in Figure 2. 


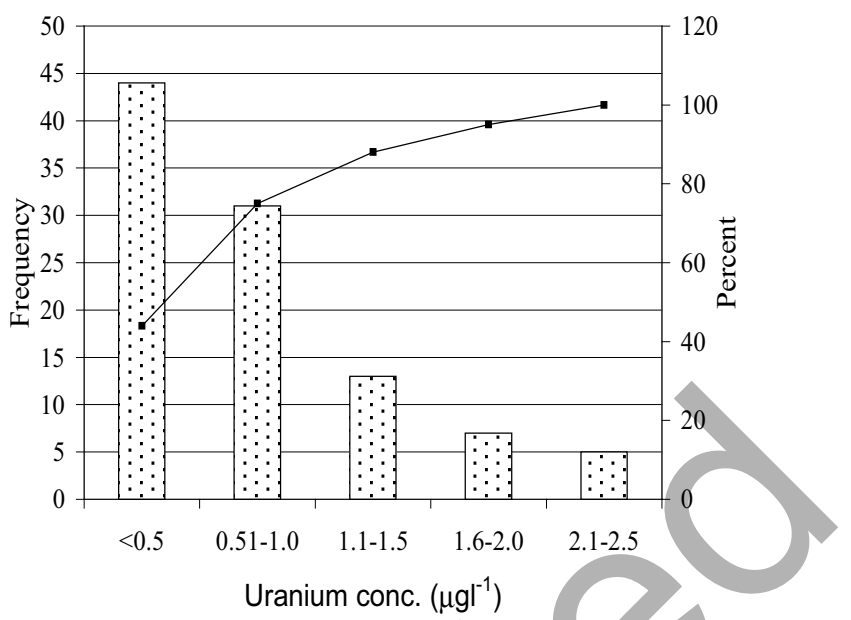

Figure 2. Frequency distribution and cumulative percentage distribution of uranium concentration in tap water.

About $44 \%$ of the samples contain less than $0.5 \mu \mathrm{g} . \mathrm{L}^{-1}$ uranium. $96 \%$ of total tap water samples contain less than $2.01 \mu \mathrm{g} . \mathrm{L}^{-1}$ uranium. Since $75 \%$ of the tap water samples contain less than $1 \mu \mathrm{g} . \mathrm{L}^{-1}$ of uranium, the radiation dose due to uranium intake will be close to the lower bound of the dose range.

\subsection{Groundwater}

Uranium concentrations in groundwater samples, collected from different parts of the city, were observed to be in the range of $0.60 \pm 0.05$ to $82 \pm 7.1 \mu \mathrm{g} . \mathrm{L}^{-1}$ with a GM of $10.07 \mu \mathrm{g} . \mathrm{L}^{-1}$. The frequency distribution of uranium in groundwater samples is presented in figure 3. Figure 3 shows that about $69 \%$ of samples contain less uranium than that recommended by the WHO $\left(15 \mu \mathrm{g} . \mathrm{L}^{-1}\right)$. About $92 \%$ of total samples are observed to contain less uranium than the limit of $60 \mu \mathrm{g} . \mathrm{L}^{-1}$ as prescribed by the Atomic Energy Regulatory Board (AERB), India (AERB, 2004). Only $4 \%$ of total samples are observed to have a uranium concentration higher than $60 \mu \mathrm{g} . \mathrm{L}^{-1}$.

\subsection{Ingestion dose}

A comparison of the mean annual ingestion dose due to uranium in tap water as well as groundwater is given in Figure 4. The mean annual dose for various age 


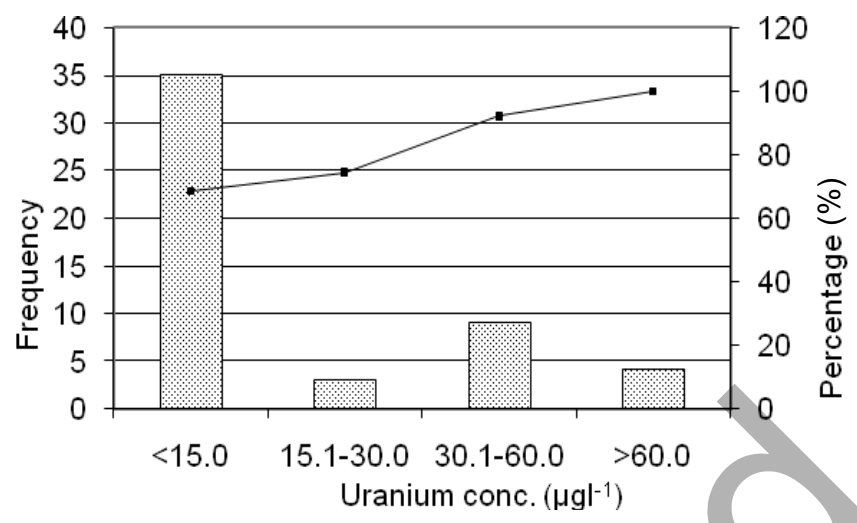

Figure 3. Frequency distribution and cumulative percentage distribution of uranium concentration in groundwater.

groups of males and females is presented (Fig. 4). It is evident from the figure that a $12.5 \%$ higher ingestion dose is observed for children (7-12 months) compared with infants (0-6 months), attributed to a higher intake rate, for tap water as well as groundwater. Though the intake of water is less, the ingestion dose for infants is marginally higher as compared with other age groups since in the case of infants, the dose coefficient is 10 times more when compared with adults. The dose in the case of males is higher when compared with females, which is due to higher water intake rates. For all the life stage groups, doses resulting from consumption of tap water are about $7 \%$ of those resulting from consumption of groundwater. Similarly, the mean annual dose for members of the public for all the age groups is 15 times lower than that due to groundwater consumption. The mean annual dose through tap water for members of the public for all the age groups is $1.08 \mu \mathrm{Sv} . \mathrm{y}^{-1}$, which is about $0.77 \%$ of the global annual effective dose from ingestion of uranium and thorium series radionuclide (UNSCEAR, 2008).

\section{Conclusion}

Estimation of natural radioactivity in the environment is required to assess the radiation dose to members of the public through various pathways. In the present study, the radiation dose due to uranium in the drinking water pathway to the public of Hyderabad, India was evaluated. The mean uranium concentration in tap water and groundwater was found to be $0.67 \mu \mathrm{g} . \mathrm{L}^{-1}$ and $10.07 \mu \mathrm{g} . \mathrm{L}^{-1}$, 


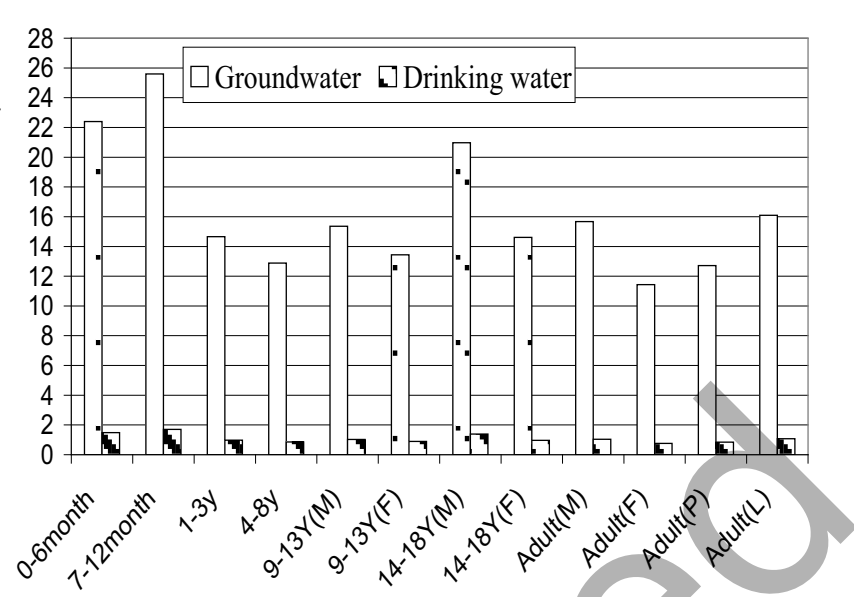

Life stage group

Figure 4. Comparison of mean annual ingestion dose for various life stage groups due to uranium in tap water and groundwater (M-Male, F-Female, P-Pregnant, L-Lactation).

respectively. The estimated annual ingestion dose due to intake of uranium through the tap water pathway for all age groups varied between 0.23 and $6.35 \mu \mathrm{Sv} . \mathrm{y}^{-1}$. In the case of consumption of groundwater, the estimated annual ingestion dose was found to vary from 0.76 to $208.19 \mu \mathrm{Sv}^{-1} \mathrm{y}^{-1}$. The mean annual ingestion dose due to uranium in tap water, which is the prime source of drinking water, is only $1.08 \mu \mathrm{Sv}, \mathrm{y}^{-1}$ for all the age groups and is 15 times lower than that of groundwater consumption.

Acknowledgement. The authors gratefully acknowledge the guidance given by Dr. A.K. Ghosh, Director, Health, Safety and Environment Group, BARC, and Dr. D.N. Sharma, Associate Director, HS\&E Group, BARC. Thanks are due to Shri R.N. Jayaraj, Chief Executive, NFC, for providing the necessary facilities for the study. The authors are also grateful to their colleagues.

\section{REFERENCES}

AERB (2004) Atomic Energy Regulatory Board Directive for limit on uranium in drinking water, India.

Almgren S., Isaksson M., Barregard L. (2008) Gamma radiation doses to people living in Western Sweden, J. Environ. Rad. 99, 394-403. 
Bronzovic M., Marovic G. (2005) Age-dependent dose assessment of Ra-226 from bottled water intake, Health Phys. 88 (5), 480-485.

Essien I.O., Sandoval D.N., Kuroda P.K. (1985) Deposition of excess amount of natural U from the atmosphere, Health Phys. 48, 325-331.

ICRP Publication 71 (1995) Age-dependent Doses to Members of the Public from Intake of Radionuclides. Part 4. Inhalation Dose Coefficients, Ann. ICRP 25 (3-4).

ICRP Publication 72 (1995) Age-dependent Doses to the Members of the Public from Intake of Radionuclides. Part 5. Compilation of Ingestion and Inhalation Coefficients, Ann. ICRP 26 (1).

ICRP publication 82 (1999) Protection of the public in situations of prolonged radiation exposure. The application of the commission's system of radiological protection to controllable radiation exposure due to natural sources and long-lived radioactive residues, Ann. ICRP 29 (1/2).

Rathore D.P.S., Tarafder P.K., Kayal M., Manjeet Kumar (2001) Application of a differential technique in laser-induced fluorimeter: simple and a precise method for the direct determination of uranium in mineralized rocks at the percentage level, Anal. Chim. Acta 434, 201-208.

Sahoo S.K., Tripathi R.M., Chakrabarty A., Mohapatra S., Sumesh C.G., Puranik V.D. (2008) Optimization of method parameters for estimation of uranium at nanogram leyel in drinking water samples by laser fluorimeter. In: Proceedings of the Indian Analytical Science Congress 2008, pp. 111-112.

Tadmor J. (1986) Atmospheric release of volatilized species of radio elements from coal-fired plants, Health Phys. 50, 270-273.

UNSCEAR (2008) United Nations Scientific Committee on the Effect of Atomic radiation, United Nations General Assembly, United Nations, New York.

US DOE (2001) Depleted uranium. Human health fact sheet. ANL.

USEPA (2000) National Primary Drinking Water Regulations; Radionuclides. Final Rule. 40 CFR Parts 9, 141 and 142.

Veselsky J.C., Kwiecinska B., Wehrstein E., Suschny O. (1988) Determination of uranium in minerals by laser fluorimeter, Analyst 113, 451-455.

www.nap.edu, Dietary reference intakes for water, Food and Nutrition Board, Institute of Medicine, National Academies Press, Washington, DC, USA. 